\title{
Evolution of clinical trials throughout history
}

Emma M. Nellhaus ${ }^{1}$, Todd H. Davies, $\mathrm{PhD}^{1}$

\section{Author Affiliations:}

1. Office of Research and Graduate Education, Marshall University Joan C. Edwards School of Medicine, Huntington, West Virginia

The authors have no financial disclosures to declare and no conflicts of interest to report.

\section{Corresponding Author:}

Todd H. Davies, PhD

Director of Research Development and Translation

Marshall University Joan C. Edwards School of Medicine

Huntington, West Virginia

Email: daviest@marshall.edu 


\section{Abstract}

The history of clinical research accounts for the high ethical, scientific, and regulatory standards represented in current practice. In this review, we aim to describe the advances that grew from failures and provide a comprehensive view of how the current gold standard of clinical practice was born. This discussion of the evolution of clinical trials considers the length of time and efforts that were made in order to designate the primary objective, which is providing improved care for our patients. A gradual, historic progression of scientific methods such as comparison of interventions, randomization, blinding, and placebos in clinical trials demonstrates how these techniques are collectively responsible for a continuous advancement of clinical care. Developments over the years have been ethical as well as clinical. The Belmont Report, which many investigators lack appreciation for due to time constraints, represents the pinnacle of ethical standards and was developed due to significant misconduct. Understanding the history of clinical research may help investigators value the responsibility of conducting human subjects' research.

\section{Keywords}

Clinical Trials, Clinical Research, History, Belmont Report 
In modern medicine, the clinical trial is the gold standard and most dominant form of clinical research. Clinical trials are well controlled and function under a strict regulatory environment. While it can be frustrating for new investigators to appreciate the necessary complexities of clinical research, recognizing that the process by which we conduct clinical trials has been evolving since the earliest days of medicine can be helpful. Some version of a controlled trial has existed for thousands of years. ${ }^{1}$ The first recorded manifestations of clinical trials were a variety of attempts to compare interventions. Clinical trials later included the incorporation of randomization, blinding, and placebos in studies with a relatively recent focus on ethic conduct of human research. Regardless of the failures and tribulations that materialized in its evolution, the history of clinical trials and the lessons learned as a result lead to a higher quality of research and better care for our patients. In this review, we will consider the advancement of clinical trials from a historical perspective to better understand the foundation and intent of conducting research for the primary benefit of the patient. As will be discussed, the history of clinical research is marked by scientific, ethical, and regulatory challenges. ${ }^{2}$

According to the International Committee of Medical Journal Editors, clinical research is defined as "any research project that prospectively assigns human subjects to intervention and comparison groups to study the cause-and-effect relationship between a medical intervention and health outcome". ${ }^{1}$ The first documented evidence of a clinical trial fitting this definition was outlined in the Book of Daniel from the Old Testament around $500 \mathrm{BC}$ in which a nutritional experiment utilized a control group. Daniel and three of his brothers were assigned to a diet of only vegetables and water and were compared with the men complying with the king's diet of meat and wine. Daniel and his brothers were noticeably healthier, thus the diet of the king's men was altered. ${ }^{3}$ Although the accuracy of this account cannot be confirmed, the idea of conducting an intervention-based trial using a concurrent control group was clearly demonstrated.

In 1537, Ambroise Paré conducted an unintentional trial, now commonly noted as the first clinical trial in history. Paré was a French military surgeon who developed a novel therapy for battlefield wounds when the standard supplies for treatment, boiling oil, ran out. ${ }^{4}$ Alternatively, Paré applied a digestive mixture of turpentine, egg yolk, and oil of roses for the sealing of soldiers' wounds that did not receive the boiling oil. Despite Paré's apprehensions that these soldiers would die from lack of cauterization, he found they were in little pain, their wounds were minimally swollen and irritated, and were overall in better condition than the soldiers who had received the hot oil. ${ }^{4}$ Although unplanned, Paré's innovation provided a method much more effective than the standard treatment. Thus, we begin to encounter the idea of advancement of care through experimentation.

Many physicians throughout history struggled with limited standard of care options. In the $17^{\text {th }}$ century, Jan Baptist van Helmont endeavored to ensure that comparisons of treatments were being made. Namely, he called attention to and rejected the traditional therapy of bloodletting and purging for fevers. ${ }^{5}$ Van Helmont argued that practitioners have a responsibility to recognize treatments that are likely to help their patients while causing minimal harm. He questioned the traditional therapies of humoral imbalance and a "fair therapeutic contest" instead suggesting therapies that considered the type and cause of disease. ${ }^{5}$ 
It was roughly one hundred years after Van Helmont's proposal that the first recorded planned clinical trial was conducted by Dr. James Lind, a Scottish naval surgeon. ${ }^{4}$ In 1747, Lind began to study scurvy, which killed thousands of British sailors annually. Lind prepared for his experiment by conducting a systematic review of what had been written previously on the treatment of scurvy, from which he extracted six proposed treatments. Outlined in his book, $A$ Treatise of the Scurvy, Lind reports that he added to his first-hand experience by evaluating reports of the disease and reports sent to him by members of the Society of Naval Services. ${ }^{6}$

The comparative trial included 12 sailors affected by scurvy that were lodged together, separated from the rest of the crew, and held on a common diet. The trial compared treatments of scurvy including cider, an elixir of vitriol, vinegar, seawater, citrus, or nutmeg. The citrus diet, which composed of oranges and lemons, proved to be a far more effective treatment than the other five. The two sailors treated with citrus received two oranges and one lemon every day, for six days. The rest of the sailors were treated for two weeks, but after half the time, the men receiving citrus were well enough to return to work. One of these sailors was even appointed nurse to the rest of the sick. The two sailors treated with cider were ordered each a quart of cider a day and Lind found that "Next to the oranges, I thought the cider had the best benefits". ${ }^{7}$ Although not comparable to the condition of the citrus group, the men given cider had improved weakness and gums. The mouths of those who used the elixir of vitriol were clearer and in better condition, although Lind expressed that he had doubted the efficacy of this treatment, as it alleviated no other symptoms. No remarkable change in condition was noted for those who took seawater, vinegar, or nutmeg. Despite the clear results of his trials, the implementation of citrus as a part of the British Naval diet did not take place until fifty years later due to cost concerns. ${ }^{2}$

The case of scurvy illustrates the motivation and economic basis for judgment during the $18^{\text {th }}$ century. The clear research evidence collected by Lind made little influence on policy and practice due to the high price and low availability of citrus fruits. Being aware of this, Lind left his readers confused about his recommendations in A Treatise of the Scurvy because of his alliance and duty to the British Navy. Although cases as extensive as Lind's are not as widespread today, economic realities remain a part of healthcare.

Following the enactment and publication of Lind's work, an increasing number of comparative studies took place. Societal challenges were answered using scientific reasoning and methodology to provide necessary advancement to the public. ${ }^{1}$ In 1865 , a French physiologist Claude Bernard published the book Introduction to the Study of Experimental Medicine. Bernard's mission was to challenge the thinking of medical professionals and urge them to consider applying scientific principles to their standards of care. A desire for knowledge and investigation of cause and effect were included in Bernard's account of what makes a substantial scientific theory. Bernard wrote, "To learn we must necessarily reason about what we have observed, compare the facts, and judge them by other facts as controls". ${ }^{8}$ His aim to establish the scientific method in medicine ultimately became a cornerstone in modern clinical trial operations based on sound scientific principles.

Around this time, we start to see new elements introduced into clinical trials that not only follow sound scientific methods, but also improve the validity of trial data. The early history of clinical trials exhibits efforts of controlling trials by using comparative groups and utilizing the scientific 
method. Following Lind's efforts, systematic and precise approach revealed a more sophisticated clinical trials mechanism.

The arrival of the placebo marked an important breakthrough in the history of clinical research. In 1863, Austin Flint conducted a trial involving patients with rheumatic fever, and compared the results of the active treatment with that of a placebo. ${ }^{9}$ Flint discovered that there was no difference in the natural history of the disease, indicating that the symptoms associated with rheumatic fever subsided naturally over time, not as a result of the orthodox drug treatment. The implementation of a placebo marked a shift in medicine in which identifying the positive benefits of active drug treatments were centralized in importance.

Patulin, an extract of Penicillium patulinum, was investigated as a treatment for the common cold. ${ }^{2}$ The patulin trial was the first double blind comparative trial, conducted by the Medical Research Council (MRC) of the United Kingdom from 1943-1944. The MRC's call for investigation and a large multi-center study was sparked by a 1943 report in the Sunday Express that claimed a MRC spokesperson found results of a preliminary patulin trial that suggested a cure for the common cold was quickly approaching. ${ }^{10}$ The Ministry of Supply, believing the report to be true, informed the MRC that they were expected to provide the raw material for manufacturing of the drug. To provide clarity to the muddled results available, a preliminary formal controlled clinical trial was conducted within the Royal Navy. These results suggested that patulin was very unlikely to be a cure, but the Council was willing to conduct a trial on a larger scale. ${ }^{11}$ The trial was conducted in widely distributed areas of Great Britain. Extensive efforts were made to ensure double blinding of the medical personnel and patients. A conclusion of the trial data showed that success of treatment was no different between the control and patulin treatment groups.

Although the data did not prove any positive effects of patulin in treatment for the common cold, the efforts were exemplary in involving researchers, funders, manufacturers, patients, and government working towards a common motive to examine a medical issue. ${ }^{10}$ The chief medical officer at one of the trial sites noted, "It is to be regretted that the work had not produced more helpful results but I do agree that negative results of this kind are very important and I only will they were more often published since I am sure that a lot of research work is done because other people have not thought it worthwhile to publish their results". ${ }^{11}$ Their use of double blinding served as a model for subsequent clinical trials.

The popularization of randomization in clinical trials was marked by the tests of streptomycin for the treatment of tuberculosis. In 1946, Austin Bradford Hill and Philip Hart were assigned by the MRC to conduct tests of the promising antibiotic, but had an extreme shortage of the drug. ${ }^{12}$ To manage their limited supply of streptomycin, participants were randomly assigned to control groups and treatment groups. Randomization eradicated the frequently observed bias in which clinicians will place healthier patients in the experimental group and sicker patients in the control group. It not only achieves similarity between groups, but it provides protection against bias. The results of Hill and Hart's study began the virtually universal use of randomization in clinical trials and were regarded as welcoming a "new era of medicine". ${ }^{12}$ 
Over several hundred years the scientific aspects of conducting clinical trials and the associated medical advances continued to improve at a seemingly exponential rate, especially in the early 1900's. The regrettable experiments that took place in the 1930's and 40's that put science over humanity proved that a greater focus on the ethics of clinical trials was necessary.

The Nuremberg Code was introduced in 1947 following the infamous Nuremberg trials in Germany in which Nazi physicians were tried for crimes committed during human experiments on concentration camp prisoners. ${ }^{13}$ Nazi physicians took advantage of prisoners by subjecting them to nonconsensual medical experiments. For example, Dr. Horst Schumann led sterilization experiments at Auschwitz in an attempt to eliminate the Jewish race. Male and female prisoners were irradiated with X-rays and given injections and suffered serious side effects, which were left untreated. ${ }^{14}$ In the Nuremberg trials, accounts of pharmaceutical testing, war-injury simulation, and other cruelties were accounted, of which many Nazi physicians were proud.

Also known as the International Code of Medical Ethics, the Nuremberg Code outlined the first basic elements of research ethics, criteria that was widely accepted but was formulated to judge those physicians who had committed despicable crimes against humanity during World War II. ${ }^{14}$ The original ten essential conditions of experiment requirements demonstrated protection of human participants in clinical trials. The document specified that voluntary consent was essential and that the benefits of research must outweigh the risks. Although the Nuremberg Code was highly publicized and a clear instruction for investigator's responsibilities, the subsequent two decades were not absent of unethical research. The Nuremberg Code had succeeded in solidifying a predominant acceptance of ethical research, but there continued to be violations by some investigators. ${ }^{15}$

The hallmark of unethical research practices is the Tuskegee syphilis study, which began in 1932 and continued for forty years without any regard to the standards established at Nuremberg. ${ }^{16}$ The study was titled "Tuskegee Study of Untreated Syphilis in the Negro Male", and was initiated when there were no known treatments for the disease. Researchers withheld treatment from the participants when, in 1947, penicillin became the standard treatment for syphilis. Patients were exploited for their vulnerability, coerced by offers of free medical care and health insurance, and researchers used extreme levels of deception by telling participants they were to be treated for "bad blood". The blatant disregard for humanity in the name of science consequently led to deaths and infections of participants' partners and children. The Tuskegee study exemplifies the necessity of providing protections for research subjects and is a reminder of the fact that humanity must be put above science. ${ }^{17}$

In 1964, the World Medical Association drafted an international manuscript promoting voluntary involvement and informed consent in human subjects research called the Declaration of Helsinki. It has since been regularly revised and encompasses international research ethics and delineates rules for "research combined with medical care" and "non-therapeutic research". ${ }^{18}$ Although not legally binding, the Declaration of Helsinki serves as the basis for laws that govern medical research in countries across the world. In the United States, the Belmont Report further solidified the principles outlined in the Declaration of Helsinki. 
Prepared in 1979 by the National Commission for the Protection of Human Subjects in Biomedical and Behavioral Research (19), the Belmont Report outlined basic ethical principles and guidelines for conducting research with human participants. Three basic principles encompass these standards: respect for persons, beneficence, and justice. ${ }^{18}$ Each principle covers several applications and serves as the foundation for guidelines concerning human participants in clinical experiments.

Clinical research evolved from trial-by-error to current customs of strict and comprehensive regulations. Scientific challenges were conquered through the implementation of experimental controls, randomization, therapy comparison, placebo, and double-blind experimentation. Ethical and regulatory advances progressed by establishing a framework of standards through the Nuremberg Code, Helsinki Declaration, and the Belmont Report. The advancements made to clinical trials throughout history have laid the foundation for ethically and scientifically sound research.

The $20^{\text {th }}$ century was clearly marked by drastic changes in medical practice with new methods of examining experimental designs being implemented throughout the century. The emergence of evidence-based practice was followed by the need for standardized procedures for assessing efficacy of therapies and guidelines for protecting the patients involved. Clinical research is necessary to provide the best possible care to current patients ${ }^{20}$ and advance available therapies, but clinical trials must continue to evolve. History has proven that standardized clinical trials answer questions other approaches of scientific investigation cannot. ${ }^{21}$ Modern challenges, including big data, pharmaceutical and device companies designing trials for marketing, monetary considerations, time constraints, and expanding public health data present new challenges and opportunities for clinical research, but require continuous improvement of research methods to assure the best possible clinical outcomes. The advanced ability to obtain and manipulate data will especially challenge privacy concerns and respect for persons. As we progress into a new era of clinical research, it is critical that investigators remember the long and storied past that led us to this point. 


\section{References}

1. Modjarrad K. A changing paradigm for medical research: The evolution of the clinical trial. Hektoen International Journal. 2016;8(Summer 2016).

2. Bhatt A. Evolution of clinical research: a history before and beyond james lind. Perspectives in clinical research. 2010;1(1):6-10.

3. Machin D, Day, S., \& Green, S. Textbook of Clinical Trials. Second ed. Chichester, West Sussex, England: John Wiley \& Sons, Ltd; 2007.

4. Gordis L. Epidemiology. 5th ed. Philadelphia, PA: Elsevier/Saunders; 2014.

5. Chalmers I. Comparing like with like: some historical milestones in the evolution of methods to create unbiased comparison groups in therapeutic experiments. International journal of epidemiology. 2001;30(5):1156-64.

6. Trohler U. Lind and scurvy: 1747 to 1795. Journal of the Royal Society of Medicine. 2005;98(11):519-22.

7. Lind J. A treatise on the scurvy. 3d ed. London,: S. Crowder etc.; 1772. xiv, 2, 559, 1 p. p.

8. Bernard C. An introduction to the study of experimental medicine. New York,: Dover Publications; 1957. 226 p. p.

9. Kaptchuck T. A brief history of the volution of methods to control observer biases in tests of treatments 2011 [Available from: http://www.jameslindlibrary.org/articles/a-brief-history-of-the-evolution-ofmethods-to-control-of-observer-biases-in-tests-of-treatments/.

10. Clarke M. The 1944 patulin trial of the British Medical Research Council. Journal of the Royal Society of Medicine. 2006;99(9):478-80.

11. Chalmers I, Clarke M. Commentary: the 1944 patulin trial: the first properly controlled multicentre trial conducted under the aegis of the British Medical Research Council. International journal of epidemiology. 2004;33(2):253-60.

12. Fda.gov. FDA and Clinical Drug Trials: A Short History 2016 [Available from: http://www.fda.gov/AboutFDA/WhatWeDo/History/Overviews/ucm304485.htm - ednref29.

13. Alabama TUo. Research Compliance: Brief History 2007 [Available from: http://osp.ua.edu/site/PRCO_History.html.

14. Benedict S, Georges JM. Nurses and the sterilization experiments of Auschwitz: a postmodernist perspective. Nursing inquiry. 2006;13(4):277-88.

15. Jotkowitz A. The Holocaust and medical ethics: the voices of the victims. Journal of medical ethics. 2008;34(12):869-70.

16. Capron AM. Henry Knowles Beecher, Jay Katz, and the Transformation of Research with Human Beings. Perspectives in biology and medicine. 2016;59(1):55-77.

17. Baker SM, Brawley OW, Marks LS. Effects of untreated syphilis in the negro male, 1932 to 1972: a closure comes to the Tuskegee study, 2004. Urology. 2005;65(6):1259-62.

18. University CG. History of Ethics. 2016.

19. Services USDoHH. The Belmont Report 2010 [Available from: http://www.hhs.gov/ohrp/regulations-andpolicy/belmont-report/.

20. Chen R, Desai NR, Ross JS, Zhang W, Chau KH, Wayda B, et al. Publication and reporting of clinical trial results: cross sectional analysis across academic medical centers. BMJ (Clinical research ed).

2016;352:i637.

21. Bothwell LE, Greene JA, Podolsky SH, Jones DS. Assessing the Gold Standard--Lessons from the History of RCTs. N Engl J Med. 2016;374(22):2175-81. 